\title{
Nonsurgical Options for the Treatment of Basal Cell Carcinoma
}

\author{
John Paoli ${ }^{1,2}$, Johan Dahlén Gyllencreutz ${ }^{3}$, Julia Fougelberg ${ }^{1,2}$, Eva Johansson Backman ${ }^{1,2}$, \\ Maja Modin ${ }^{1,2}$, Sam Polesie ${ }^{1,2}$, Oscar Zaar ${ }^{1,2}$
}

\begin{abstract}
1 Department of Dermatology and Venereology, Institute of Clinical Sciences, Sahlgrenska Academy, University of Gothenburg, Gothenburg, Sweden

2 Region Västra Götaland, Sahlgrenska University Hospital, Department of Dermatology and Venereology, Gothenburg, Sweden

3 Department of Dermatology and Venereology, Skaraborg Hospital, Skövde, Sweden
\end{abstract}

Key words: basal cell carcinoma, destructive therapy, topical drugs, radiotherapy, hedgehog inhibitors

Citation: Paoli J, Dahlén Gyllencreutz J, Fougelberg J, Johansson Backman E, Modin M, Polesie S, Zaar O. Nonsurgical options for the treatment of basal cell carcinoma. Dermatol Pract Concept. 2019;9(2):75-81. DOI: https://doi.org/10.5826/dpc.0902a01

Accepted: November 15, 2018; Published: April 30, 2019

Copyright: @2019 Paoli et al. This is an open-access article distributed under the terms of the Creative Commons Attribution License, which permits unrestricted use, distribution, and reproduction in any medium, provided the original author and source are credited.

Funding: None.

Competing interests: The authors have no conflicts of interest to disclose.

Authorship: All authors have contributed significantly to this publication.

Corresponding author: John Paoli, MD, Assoc. Prof, Department of Dermatology and Venereology, Sahlgrenska University Hospital, 413 45 Gothenburg, Sweden. Email: John.paoli@vgregion.se

ABSTRACT Objectives: The aim of this review article is to summarize the effectiveness, potential adverse events, and indications of the main nonsurgical treatment alternatives for basal cell carcinoma.

Methods: An extensive literature review was carried out. The most relevant articles were discussed and selected by the authors in order to provide a brief but evidence-based overview of the most common nonsurgical methods used for treating basal cell carcinoma.

Results: Although surgery and Mohs micrographic surgery are often considered the optimal treatment options for basal cell carcinoma, these tumors can also be treated successfully with destructive techniques (eg, curettage alone, cryosurgery, or electrodesiccation), photodynamic therapy, topical drugs (eg, 5-fluorouracil, imiquimod, or ingenol mebutate), radiotherapy, or hedgehog pathway inhibitors. When choosing between these alternatives, physicians must take into consideration the tumor's size, location, and histopathological subtype. Special care should be taken when treating recurrent tumors. Furthermore, physician experience is of great importance when using destructive techniques. Finally, patient preference, potential adverse events, and cosmetic outcome should also be considered.

Conclusions: Dermatologists and physicians treating basal cell carcinoma should have knowledge of and experience with the large arsenal of therapeutic alternatives available for the successful, safe, and individualized management of patients with basal cell carcinoma.

\section{Introduction}

Basal cell carcinoma (BCC) is by far the most common cancer type in humans [1]. In Europe, reports show BCC incidence rates between 77 and 158 per 100,000 person-years age-standardized to the European standard population [1]. Exposure from ultraviolet radiation is believed to be the main risk factor for developing BCCs. This belief is supported by the fact that the majority of BCCs are found on sun-exposed body parts in middle-aged to elderly people $[1,2]$. The exact 
origin of BCC is not established, but they are considered to arise from keratinocyte cells located in the basal layer and in the dermo-epidermal junction zone [3].

The World Health Organization classification of BCC includes superficial, nodular, micronodular, and infiltrating basal cell carcinoma. Moreover, the group includes fibroepithelial basal cell carcinoma with adnexal differentiation, basosquamous carcinoma, and keratotic basal cell carcinoma [4].

The infiltrative, morpheaform, and micronodular subtypes grow in a more aggressive way, whereas superficial and nodular subtypes generally have a less aggressive course and generally respond better to treatment [5].

Clinically, dermoscopy can assist physicians in the correct diagnosis of BCC, including the histopathological subtype, with relatively high diagnostic accuracy [6-8]. The first articles on BCC focused on pigmented BCCs showing a lack of pigment network in combination with blue-gray ovoid nests, multiple blue-gray dots/globules, leaf-like areas, spoke wheel/concentric areas, ulceration, and/or arborizing vessels $[6,7,9]$. In nodular BCC (nBCC), arborizing vessels are a common finding, sometimes together with ulceration [10]. Under polarized light, shiny white lines can also be found [11]. Superficial BCCs (sBCCs) characteristically show fine, short telangiectasias on a whitish-red background and multiple erosions $[7,8,12]$. The dermoscopic findings in more aggressive forms of BCC are less well studied. In infiltrative BCCs, arborizing vessels are usually thinner than in nBCCs. Other findings include white-red structureless areas and ulceration. The morpheaform variant is often feature-poor, even when using dermoscopy. A white background can often be seen, sometimes together with a smaller number of thin arborizing vessels [13].

During the latest decades, insights into genetic and molecular changes behind the origin of BCC have increased. These understandings have to some extent been derived from studying patients with different genetic syndromes predisposing them to BCC development (eg, Gorlin syndrome) who have a higher risk of developing BCCs [14]. Individuals with Gorlin syndrome develop multiple BCCs starting at an early age and the responsible mutation lies in the Hedgehog $(\mathrm{Hh})$ receptor Patched 1 (PTCH1) gene that mediates Sonic Hh signaling. Research has reported abnormal function and mutations in PTCH1 in up to $90 \%$ of BCCs, making it a target for drug development [3].

With regard to the management of BCC, surgery (including Mohs micrographic surgery) is considered the gold standard $[1,15,16]$. Nevertheless, with the rising number of patients with BCC, increasing health care costs, and the lack of access to dermatologists in many countries, nonsurgical options may be considered. Many low-risk tumors can be successfully managed with destructive methods, photodynamic therapy (PDT), or topical medications, while advanced or inoperable BCCs may benefit from radiotherapy or hedgehog pathway inhibitors (HPIs) $[1,16,17]$.

The aim of this review is to summarize the effectiveness, potential adverse events, and indications of the main nonsurgical treatment alternatives for BCC.

\section{Destructive Methods}

\section{Curettage Alone}

BCCs amenable to treatment with curettage alone are primary tumors with a superficial or nodular growth pattern with well-defined borders not involving the free margin of the eyelid, mucosal lip, or subcutaneous fat. For nBCCs, the size is recommended to be $<6 \mathrm{~mm}$ in high-risk areas, and below $20 \mathrm{~mm}$ elsewhere. The few studies on curettage alone were carried out many years ago and did not use a unifying technique. In some countries, including the USA, a shave biopsy is performed first, removing the tumor almost completely prior to curettage. In other countries, including Sweden, curettage is performed directly, removing the entire tumor with the curette. Nevertheless, 3 retrospective studies have reported similar clearance rates of $89.9 \%-96.0 \%$ after 5 years of follow-up. Better cosmesis with minimal hypopigmentation or scarring was observed in patients treated with curettage alone compared with those treated with curettage and electrodesiccation (C\&ED) [18-20].

\section{Curettage and Electrodesiccation}

Although C\&ED has been used for decades as a simple and easily performed therapy for low-risk BCCs, there is a lack of randomized controlled studies on the method. Several retrospective studies show its effectiveness for correctly selected lesions (93.0\%-96.9\% clearance rates after 5 years of followup), but many studies fail to provide precise descriptions on the materials and technical protocols that are used [21,22]. In the latest American Academy of Dermatology guidelines, C\&ED is one of the recommended treatment options for carefully selected low-risk primary lesions [16]. In terminal hair-bearing skin, with a potential follicular extension of the tumor (scalp, pubic, and axillary regions as well as the beard area in men), C\&ED is considered less effective [17]. The effectiveness depends heavily on the physician's skills and technique, and therefore proper training is important $[23,24]$. Furthermore, the cosmetic outcome is regarded as inferior compared with standard excision and therefore it is best avoided in cosmetically sensitive areas [25].

\section{Cryotherapy}

Cryotherapy with liquid nitrogen $\left(-196.5^{\circ} \mathrm{C}\right)$ has been used to treat nonmelanoma skin cancer since the early 1960s [26]. It is a well-established treatment method for small, well-defined 
primary BCCs without sclerosing or infiltrative growth patterns. Location below the knee is a relative contraindication because of prolonged wound healing [27]. Large treatment series have shown clearance rates of $97 \%-99 \%$ after at least 5 years of follow-up [28,29]. As for C\&ED, there are few prospective randomized trials on cryotherapy for BCCs and different techniques and protocols are used, making comparisons difficult. Most studies on cryotherapy involve prior curettage. Curettage is regarded as a help in delineating the lateral extension and depth of the tumor and also to diminish the amount of tumor mass that has to be sloughed off during the healing process following cryotherapy.

Three prospective studies using a standardized curettage and cryotherapy protocol have reported very high clearance rates of $>98 \%$ for BCCs located in the face and scalp area, especially on the nose and ear [29-31]. The protocol in all 3 studies involves curettage followed by a double freeze-thaw cycle. Thorough curettage with different sized curettes is first used to debulk the tumor and to identify the lateral and deep extension. Following hemostasis with a 50\% iron chloride solution, a 3-mm thick, open and appropriately sized neoprene cone is placed around the ulcerated area. Subsequently, freezing takes place with maximal continuous liquid nitrogen spray using a hand-held Cry-Ac (Brymill Corp., Ellington, CT, USA) through a size B nozzle, held horizontally and at a distance of approximately $1 \mathrm{~cm}$ while moved in circular motions over the treatment area. Freezing is interrupted when the lateral spread of freeze (halo) has reached a minimum of $5 \mathrm{~mm}$ outside the tumor border or 1.0-1.5 mm outside the neoprene cone. The thaw time of the halo should last at least 60 seconds. After complete thawing, the freeze-thaw cycle is repeated.

Cryotherapy in a double freeze-thaw cycle as described above but without previous curettage has also shown excellent clearance rates for well-defined BCCs of the eyelids with a 10 -year recurrence rate of $<0.5 \%$ [32].

\section{Photodynamic Therapy}

PDT is an alternative approach to treat superficial nonmelanoma skin cancer, including BCC [33]. PDT for BCC is often well tolerated, but pain and/or a burning sensation is often experienced during the illumination phase [34]. After PDT, localized erythema and edema are common, followed by the formation of erosions and crusts with healing over a period of 2-6 weeks [1]. PDT is considered an interesting alternative treatment because it is noninvasive, it targets neoplastic cells selectively, it is cost-effective, and it offers a good cosmetic outcome [35,36].

There are many different treatment protocols for PDT and results vary depending on the BCC subtype [36-42], prior curettage $[36,38,40,41,43]$, and number of PDT sessions
$[37,44]$, while the photosensitizing prodrug used does not seem to influence the outcome $[45,46]$. The histopathological subtype influences the result of PDT as pigmented, morphoeic, and infiltrative BCCs are more resistant to treatment. The clearance rates following PDT for sBCCs range from $76 \%$ to $82 \%$ in several studies $[37,38,42]$, but could be as low as $58 \%$ [47]. The success rate is slightly lower for nBCCs in general (53\%-76\%) [36,39-41]. Debulking nBCCs with curettage prior to PDT provides long-term clearance rates of $62 \%-73 \%[36,41,43]$ compared with light curettage without debulking, which provides more varying clearance rates of $33 \%-76 \%$ [38,40]. Fewer recurrences have been observed when patients with nonaggressive BCCs receive PDT in 2 sessions (91\%) compared with only 1 session of PDT (68\%) with a follow-up of 6 years [48]. Three randomized controlled trials have compared the efficacy of aminolevulinic acid PDT and methyl aminolevulinate (MAL) PDT for BCCs, showing comparable effectiveness [45,46,49].

Modifications to PDT have been tested to decrease the recurrence rate for BCC. Daylight PDT may provide similar clearance rates compared with conventional PDT, but with less pain [50]. However, larger studies with longer follow-up times are needed to confirm its effectiveness. Treating BCCs with a fractional laser prior to PDT may improve the depth of penetration of the prodrug and has shown lower recurrence rates than conventional PDT for high-risk BCCs (19\% vs $44 \%$ ) [51].

A meta-analysis by Wang et al showed no significant differences in recurrence rates when comparing PDT to either cryotherapy or pharmacological treatment. However, surgery proved to have significantly lower risk of failure when compared with PDT. The same analysis showed a "good to excellent" cosmetic result comparing PDT to surgery or cryotherapy, but no significant differences when comparing it to other medical treatments [52].

\section{Topical Medication}

\section{5-Fluorouracil}

Topical 5-fluorouracil (5-FU) 5\% inhibits DNA synthesis and was the first topical therapy approved for the treatment of sBCC [53]. However, compared with PDT and imiquimod, fewer well-designed studies evaluating this indication have been published $[47,54]$. In a prospective, single-arm, clinical study, 29 patients with 31 histopathologically confirmed sBCCs were treated with 5-FU applied twice daily for up to 12 weeks. The lesions were excised 3 weeks after treatment with a histopathological clearance rate of $90 \%$ [53]. A single-blind, noninferiority, randomized controlled trial with 601 histopathologically confirmed sBCCs compared the use of PDT ( 2 sessions with an interval of 1 week) with topical imiquimod (once daily, 5 times/week for 6 weeks) and 
topical 5-FU (twice daily for 4 weeks). In this study, topical 5-FU was noninferior to PDT and imiquimod was superior to PDT. Furthermore, topical 5-FU and imiquimod were more often associated with mild to moderate adverse events in the treatment area than was PDT [55]. A 5-year follow-up on the study recently declared the probability of tumor-free survival to be $62.7 \%$ for PDT, $80.5 \%$ for imiquimod, and $70.0 \%$ for 5-FU [56]. In summary, 5-FU is approved for treatment of sBCC, appears to be noninferior to PDT, and is generally well tolerated. Therefore, it can be considered a therapeutic option in the treatment of sBCC.

\section{Imiquimod}

Imiquimod works as an immunomodulator by activating Toll-like receptor 7 , resulting in stimulation of dendritic cells residing in both the epidermis and dermis to attract natural killer cells and produce cytokines via proliferation of B lymphocytes. The treatment regimen is classically topical imiquimod $5 \%$ applied once daily, 5 days per week for 6 weeks in sBCC and 12 weeks in nBCC.

Jansen et al recently presented 1-, 3-, and 5-year efficacy data on imiquimod in more than 100 histopathologically confirmed sBCCs. After 1 year, $83.5 \%$ of the sBCCs were successfully treated and at 5 years $80.5 \%$ still showed no recurrences [56]. Similar findings were made by Bath-Hextall et al, who treated 254 BCC lesions (both superficial and nodular) with imiquimod with clearance rates of $85.1 \%$ for sBCCs and $81.8 \%$ for nBCCs at 3 years [57]. Williams et al later presented 5-year results from the same cohort with an $83.8 \%$ success rate for $\mathrm{sBCC}$ and $81.1 \%$ for nBCCs [58]. In these 2 studies, the recurrences were based on clinical assessment and were not histopathologically confirmed.

With regard to aesthetic outcome, Arits et al reported in a large randomized controlled trial that imiquimod and MAL-PDT have similar results with good to excellent outcomes in $61.4 \%$ and $62.4 \%$ of the cases, respectively [55]. A cost-effectiveness study on topical treatments for BCC show that imiquimod and 5-FU are superior to MAL-PDT at 12 months but longer follow-up time is needed to assess the costeffectiveness between imiquimod and 5-FU [59].

When compared with MAL-PDT for sBCCs, imiquimod is known to be superior in general but a subgroup analysis performed by Roozeboom et al in a randomized controlled trial with 200 lesions in each treatment arm revealed that PDT might outperform imiquimod. Also, in patients over 60 years of age with sBCC on the lower extremities, MAL-PDT was significantly more effective than imiquimod at 1 -year follow-up [47].

\section{Ingenol Mebutate}

Ingenol mebutate (IM) gel is a topical agent derived from sap from the plant Euphorbia peplus, which is approved for treatment of actinic keratosis through induction of primary necrosis of tumor cells, and neutrophil-mediated, antibodydependent cellular cytotoxicity of residual malignant cells [60]. IM comes in 2 concentrations: $0.015 \%$ for the face and $0.05 \%$ for the trunk. Recently, several case reports of successful off-label treatment of sBCC with topical IM have been reported [61-65]. In a retrospective study, including 7 patients with sBCC treated with IM gel $0.05 \%$ once daily for $2-7$ days, there were no clinical signs of recurrence after 2-14 months [66]. A phase IIa study including 60 patients with safety as the primary endpoint evaluated the treatment of sBCC with IM at concentrations of $0.01 / 0.025 / 0.05 \%$ applied for 2 consecutive days or on day 1 and 8 . The incidence of adverse events was generally low. The efficacy (secondary endpoint) appeared to be dose-related with up to $63 \%$ histopathological clearance with the highest dosage after 12 weeks [60]. Another phase I/II clinical study including 28 BCCs (6 nBCCs and 22 sBCCs), which were unresponsive to earlier treatment or unsuitable for surgery, treated with sap from E peplus once daily for 3 days, showed complete clinical clearance in $82 \%$ after 1 month and 57\% after 2-31 months, while sBCCs smaller than $16 \mathrm{~mm}(\mathrm{n}=9)$ had a $78 \%$ clearance after a mean follow-up of 15 months [67]. For sBCCs unsuitable for conventional treatment, IM can offer an alternative treatment strategy in selected patients, but close follow-up is advised.

\section{Radiotherapy}

The vast majority of BCCs are treated with surgery or the destructive methods listed above. Although rare, some BCCs are neglected and/or are inaccessible to standard treatments. In these rare cases, radiotherapy (RT) may be considered. Patients unwilling to undergo surgery or with significant comorbidities might also be candidates for this treatment option. There are 3 different radiation modalities: low-energy X-rays, brachytherapy, and high-energy RT. Treatment success is generally $90 \%$, which is in line with surgical treatment [68]. However, only a few clinical trials have been conducted, and there is no consensus on optimal treatment duration and which radiation modality should be selected [69]. RT is given in fractions of 30-70 Gy over 2-7 weeks, which requires multiple visits to a specialized clinic. A prospective randomized trial selecting patients for surgery or RT with a subrandomization to long and short RT would be helpful to clarify which radiation modality is superior with regard to recurrence rates. Due to long-term consequences such as radiodermatitis and the risk of secondary malignancies, mainly patients over 60 years should be considered for RT. In a Canadian study, the cost of managing high-risk facial BCCs with RT was higher than that of Mohs micrographic surgery [70]. Moreover, prior to initiation, a multidisciplinary decision with an experienced radiation oncologist and thorough patient information is 
mandatory. Finally, recurring BCC after RT is a surgical challenge and this should be carefully considered.

\section{Hedgehog Pathway Inhibitors}

HPIs have emerged as an important treatment option for locally advanced BCC or in the rare event of metastatic BCC [71]. There are 2 commercially available HPIs: vismodegib and sonidegib. In a systematic review investigating vismodegib, $65 \%$ of patients with locally advanced BCC experienced complete or partial response, whereas $31 \%$ had a complete response rate. The corresponding numbers for metastatic BCC were $34 \%$ and $4 \%$, respectively. However, among 803 patients, $31 \%$ discontinued the treatment because of side effects [72]. Muscle spasms, dysgeusia, fatigue, weight loss, and alopecia are common. In addition, treatment with HPI is associated with high costs (approximately €4500/month).

Neoadjuvant treatment with HPIs prior to surgery for selected cases has been evaluated with positive results [73], but prospective randomized controlled trials are lacking. When selecting this treatment option there is risk for multifocal remaining disease, which might complicate surgery. Although there is no consensus, concurrent treatment with RT and HPIs may be evaluated in selected cases [74].

\section{Conclusions}

This review shows that several effective nonsurgical therapeutic alternatives exist for the successful, safe, and individualized management of BCC. Physicians managing patients with BCCs need to be aware of the indications, effectiveness, and potential adverse events of this wide range of treatment methods so that they are able to select the most adequate method for each patient and clinical scenario. Physicians also need specific training in each method in order to reproduce the same clinical outcome seen in the aforementioned studies. Furthermore, physicians should be aware of the lack of randomized controlled trials for many of the nonsurgical procedures mentioned, even though they are regularly carried out by the dermatological community.

More extensive guideline documents for the general management of BCCs have been published by associations such as the European Dermatology Forum [1], the American Academy of Dermatology [16], and the National Comprehensive Cancer Network [17], and this review does not intend to substitute any of them. However, the techniques mentioned herein can provide excellent results for the ever-growing number of patients who can benefit from nonsurgical approaches to managing BCC as long as the treating physician takes into account tumor size, location, and histopathological subtype; whether the tumor is primary or recurrent; their own experi- ence with the techniques; the expected adverse events; patient preference; and cosmetic outcome.

\section{References}

1. Trakatelli M, Morton C, Nagore E, et al. Update of the European guidelines for basal cell carcinoma management. Eur J Dermatol. 2014;24(3):312-329.

2. El Ghissassi F, Baan R, Straif K, et al. A review of human carcinogens, part D: radiation. Lancet Oncol. 2009;10(8):751-752.

3. Kasper M, Jaks V, Hohl D, Toftgard R. Basal cell carcinoma: molecular biology and potential new therapies. J Clin Invest. 2012;122(2):455-463.

4. LeBoit PE. Pathology and Genetics of Skin Tumours. IARC Press; 2006.

5. Weinstock MA. Epidemiology of nonmelanoma skin cancer: clinical issues, definitions, and classification. J Invest Dermatol. 1994;102(6):4S-5S.

6. Altamura D, Menzies SW, Argenziano G, et al. Dermatoscopy of basal cell carcinoma: morphologic variability of global and local features and accuracy of diagnosis. J Am Acad Dermatol. 2010;62(1):67-75.

7. Lallas A, Tzellos T, Kyrgidis A, et al. Accuracy of dermoscopic criteria for discriminating superficial from other subtypes of basal cell carcinoma. J Am Acad Dermatol. 2014;70(2):303-311.

8. Suppa M, Micantonio T, Di Stefani A, et al. Dermoscopic variability of basal cell carcinoma according to clinical type and anatomic location. J Eur Acad Dermatol Venereol. 2015;29(9):1732-1741.

9. Menzies SW, Westerhoff K, Rabinovitz H, Kopf AW, McCarthy WH, Katz B. Surface microscopy of pigmented basal cell carcinoma. Arch Dermatol. 2000;136(8):1012-1016.

10. Argenziano G, Zalaudek I, Corona R, et al. Vascular structures in skin tumors: a dermoscopy study. Arch Dermatol. 2004;140(12):1485-1489.

11. Liebman TN, Jaimes-Lopez N, Balagula Y, et al. Dermoscopic features of basal cell carcinomas: differences in appearance under non-polarized and polarized light. Dermatol Surg. 2012;38(3):392-399.

12. Giacomel J, Zalaudek I. Dermoscopy of superficial basal cell carcinoma. Dermatol Surg. 2005;31(12):1710-1713.

13. Lallas A, Apalla Z, Argenziano G, et al. The dermatoscopic universe of basal cell carcinoma. Dermatol Pract Concept. 2014;4(3):11-24.

14. Castori M, Morrone A, Kanitakis J, Grammatico P. Genetic skin diseases predisposing to basal cell carcinoma. Eur J Dermatol. 2012;22(3):299-309.

15. Bath-Hextall F, Bong J, Perkins W, Williams H. Interventions for basal cell carcinoma of the skin: systematic review. BMJ. 2004;329(7468):705.

16. Kim JYS, Kozlow JH, Mittal B, Moyer J, Olencki T, Rodgers P. Guidelines of care for the management of basal cell carcinoma. $J$ Am Acad Dermatol. 2018;78(3):540-559.

17. National Comprehensive Cancer Center. NCCN Clinical Practice Guidelines in Oncology. Basal Cell Skin Cancer (Version 1.2018). 2017. https://www.nccn.org/professionals/physician_gls/pdf/ nmsc.pdf. Accessed August 7, 2018.

18. Barlow JO, Zalla MJ, Kyle A, DiCaudo DJ, Lim KK, Yiannias JA. Treatment of basal cell carcinoma with curettage alone. J Am Acad Dermatol. 2006;54(6):1039-1045. 
19. McDaniel WE. Therapy for basal cell epitheliomas by curettage only: further study. Arch Dermatol. 1983;119(11):901-903.

20. Reymann F. 15 years' experience with treatment of basal cell carcinomas of the skin with curettage. Acta Derm Venereol Suppl (Stockb). 1985;120:56-59.

21. Knox JM, Lyles TW, Shapiro EM, Martin RD. Curettage and electrodesiccation in the treatment of skin cancer. Arch Dermatol. 1960;82:197-204.

22. Williamson GS, Jackson R. Treatment of basal cell carcinoma by electrodesiccation and curettage. Can Med Assoc J. 1962;86:855862.

23. Kopf AW, Bart RS, Schrager D, Lazar M, Popkin GL. Curettageelectrodesiccation treatment of basal cell carcinomas. Arch Dermatol. 1977;113(4):439-443.

24. Sweet RD. The treatment of basal cell carcinoma by curettage. $\mathrm{Br}$ J Dermatol. 1963;75:137-148.

25. Rodriguez-Vigil T, Vazquez-Lopez F, Perez-Oliva N. Recurrence rates of primary basal cell carcinoma in facial risk areas treated with curettage and electrodesiccation. J Am Acad Dermatol. 2007;56(1):91-95.

26. Copper IS. Cryogenic surgery: a new method of destruction or extirpation of benign or malignant tissues. $N$ Engl J Med. 1963;268:743-749.

27. Zacarian SA. Cryosurgery of cutaneous carcinomas. An 18-year study of 3,022 patients with 4,228 carcinomas. J Am Acad Dermatol. 1983;9(6):947-956.

28. Kuflik EG. Cryosurgery for skin cancer: 30 -year experience and cure rates. Dermatol Surg. 2004;30(2 Pt 2):297-300.

29. Lindemalm-Lundstam B, Dalenback J. Prospective follow-up after curettage-cryosurgery for scalp and face skin cancers. $\mathrm{Br} J$ Dermatol. 2009;161(3):568-576.

30. Nordin P, Larko O, Stenquist B. Five-year results of curettagecryosurgery of selected large primary basal cell carcinomas on the nose: an alternative treatment in a geographical area underserved by Mohs' surgery. Br J Dermatol. 1997;136(2):180-183.

31. Nordin P, Stenquist B. Five-year results of curettage-cryosurgery for 100 consecutive auricular non-melanoma skin cancers. J Laryngol Otol. 2002;116(11):893-898.

32. Lindgren $G$, Larko O. Cryosurgery of eyelid basal cell carcinomas including 781 cases treated over 30 years. Acta Ophthalmol. 2014;92(8):787-792.

33. Morton CA, Szeimies RM, Sidoroff A, Braathen LR. European guidelines for topical photodynamic therapy part 1: treatment delivery and current indications-actinic keratoses, Bowen's disease, basal cell carcinoma. J Eur Acad Dermatol Venereol. 2013;27(5):536-544.

34. Ibbotson SH. Adverse effects of topical photodynamic therapy. Photodermatol Photoimmunol Photomed. 2011;27(3):116-130.

35. Caekelbergh K, Annemans L, Lambert J, Roelandts R. Economic evaluation of methyl aminolaevulinate-based photodynamic therapy in the management of actinic keratosis and basal cell carcinoma. Br J Dermatol. 2006;155(4):784-790.

36. Foley P, Freeman M, Menter A, et al. Photodynamic therapy with methyl aminolevulinate for primary nodular basal cell carcinoma: results of two randomized studies. Int J Dermatol. 2009;48(11):1236-1245.

37. Basset-Seguin N, Ibbotson SH, Emtestam L, et al. Topical methyl aminolaevulinate photodynamic therapy versus cryotherapy for superficial basal cell carcinoma: a 5 year randomized trial. Eur J Dermatol. 2008;18(5):547-553.
38. Fantini F, Greco A, Del Giovane C, et al. Photodynamic therapy for basal cell carcinoma: clinical and pathological determinants of response. J Eur Acad Dermatol Venereol. 2011;25(8):896-901.

39. Peng Q, Warloe T, Berg K, et al. 5-Aminolevulinic acid-based photodynamic therapy: clinical research and future challenges. Cancer. 1997;79(12):2282-2308.

40. Rhodes LE, de Rie MA, Leifsdottir R, et al. Five-year follow-up of a randomized, prospective trial of topical methyl aminolevulinate photodynamic therapy vs surgery for nodular basal cell carcinoma. Arch Dermatol. 2007;143(9):1131-1136.

41. Soler AM, Warloe T, Tausjo J, Berner A. Photodynamic therapy by topical aminolevulinic acid, dimethylsulphoxide and curettage in nodular basal cell carcinoma: a one-year follow-up study. Acta Derm Venereol. 1999;79(3):204-206.

42. Szeimies RM, Ibbotson S, Murrell DF, et al. A clinical study comparing methyl aminolevulinate photodynamic therapy and surgery in small superficial basal cell carcinoma $(8-20 \mathrm{~mm})$, with a 12 -month follow-up. J Eur Acad Dermatol Venereol. 2008;22(11):1302-1311.

43. Berroeta L, Clark C, Dawe RS, Ibbotson SH, Fleming CJ. A randomized study of minimal curettage followed by topical photodynamic therapy compared with surgical excision for low-risk nodular basal cell carcinoma. Br J Dermatol. 2007;157(2):401403.

44. Wang I, Bendsoe N, Klinteberg CA, et al. Photodynamic therapy vs. cryosurgery of basal cell carcinomas: results of a phase III clinical trial. Br J Dermatol. 2001;144(4):832-840.

45. Kuijpers DI, Thissen MR, Thissen CA, Neumann MH. Similar effectiveness of methyl aminolevulinate and 5 -aminolevulinate in topical photodynamic therapy for nodular basal cell carcinoma. J Drugs Dermatol. 2006;5(7):642-645.

46. Schleier P, Berndt A, Kolossa S, Zenk W, Hyckel P, SchultzeMosgau S. Comparison of aminolevulinic acid (ALA)-thermogelPDT with methyl-ALA-thermogel-PDT in basal cell carcinoma. Photodiagnosis Photodyn Ther. 2007;4(3):197-201.

47. Roozeboom MH, Arits AH, Mosterd K, et al. Three-year followup results of photodynamic therapy vs. imiquimod vs. fluorouracil for treatment of superficial basal cell carcinoma: a single-blind, noninferiority, randomized controlled trial. J Invest Dermatol. 2016;136(8):1568-1574.

48. Christensen E, Skogvoll E, Viset T, Warloe T, Sundstrom S. Photodynamic therapy with 5-aminolaevulinic acid, dimethylsulfoxide and curettage in basal cell carcinoma: a 6-year clinical and histological follow-up. J Eur Acad Dermatol Venereol. 2009;23(1):5866.

49. Morton CA, Dominicus R, Radny P, et al. A randomized, multinational, noninferiority, phase III trial to evaluate the safety and efficacy of BF-200 aminolaevulinic acid gel vs. methyl aminolaevulinate cream in the treatment of nonaggressive basal cell carcinoma with photodynamic therapy. Br J Dermatol. 2018;179(2):309-319.

50. Wiegell SR, Skodt V, Wulf HC. Daylight-mediated photodynamic therapy of basal cell carcinomas: an explorative study. J Eur Acad Dermatol Venereol. 2014;28(2):169-175.

51. Haak CS, Togsverd-Bo K, Thaysen-Petersen D, et al. Fractional laser-mediated photodynamic therapy of high-risk basal cell carcinomas: a randomized clinical trial. Br J Dermatol. 2015;172(1):215-222.

52. Wang H, Xu Y, Shi J, Gao X, Geng L. Photodynamic therapy in the treatment of basal cell carcinoma: a systematic review 
and meta-analysis. Photodermatol Photoimmunol Photomed. 2015;31(1):44-53.

53. Gross K, Kircik L, Kricorian G. 5\% 5-Fluorouracil cream for the treatment of small superficial basal cell carcinoma: efficacy, tolerability, cosmetic outcome, and patient satisfaction. Dermatol Surg. 2007;33(4):433-439; discussion 440.

54. Love WE, Bernhard JD, Bordeaux JS. Topical imiquimod or fluorouracil therapy for basal and squamous cell carcinoma: a systematic review. Arch Dermatol. 2009;145(12):1431-1438.

55. Arits AH, Mosterd K, Essers BA, et al. Photodynamic therapy versus topical imiquimod versus topical fluorouracil for treatment of superficial basal-cell carcinoma: a single blind, non-inferiority, randomised controlled trial. Lancet Oncol. 2013;14(7):647-654.

56. Jansen MHE, Mosterd K, Arits A, et al. Five-year results of a randomized controlled trial comparing effectiveness of photodynamic therapy, topical imiquimod, and topical 5 -fluorouracil in patients with superficial basal cell carcinoma. J Invest Dermatol. 2018;138(3):527-533.

57. Bath-Hextall F, Ozolins M, Armstrong SJ, et al. Surgical excision versus imiquimod $5 \%$ cream for nodular and superficial basalcell carcinoma (SINS): a multicentre, non-inferiority, randomised controlled trial. Lancet Oncol. 2014;15(1):96-105.

58. Williams HC, Bath-Hextall F, Ozolins M, et al. Surgery versus $5 \%$ imiquimod for nodular and superficial basal cell carcinoma: 5 -year results of the SINS randomized controlled trial. J Invest Dermatol. 2017;137(3):614-619.

59. Arits AH, Spoorenberg E, Mosterd K, Nelemans P, KellenersSmeets NW, Essers BA. Cost-effectiveness of topical imiquimod and fluorouracil vs. photodynamic therapy for treatment of superficial basal-cell carcinoma. Br J Dermatol. 2014;171(6):15011507.

60. Siller G, Rosen R, Freeman M, Welburn P, Katsamas J, Ogbourne SM. PEP005 (ingenol mebutate) gel for the topical treatment of superficial basal cell carcinoma: results of a randomized phase IIa trial. Australas J Dermatol. 2010;51(2):99-105.

61. Cantisani C, Paolino G, Cantoresi F, Faina V, Richetta AG, Calvieri S. Superficial basal cell carcinoma successfully treated with ingenol mebutate gel 0.05\%. Dermatol Ther. 2014;27(6):352354.

62. Diluvio L, Bavetta M, Di Prete M, Orlandi A, Bianchi L, Campione E. Dermoscopic monitoring of efficacy of ingenol mebutate in the treatment of pigmented and non-pigmented basal cell carcinomas. Dermatol Ther. 2017;30(1).

63. Izzi S, Sorgi P, Piemonte P, Carbone A, Frascione P. Successfully treated superficial basal cell carcinomas with ingenol mebutate $0.05 \%$ gel: report of twenty cases. Dermatol Ther. 2016;29(6):470-472.

64. Jung YS, Lee JH, Bae JM, Kim GM. Superficial basal cell carcinoma treated with two cycles of ingenol mebutate gel 0.015. Ann Dermatol. 2016;28(6):796-797.

65. Stieger M, Hunger RE. Ingenol mebutate treatment in a patient with Gorlin syndrome. Dermatology. 2016;232(Suppl 1):29-31.

66. Bettencourt MS. Treatment of superficial basal cell carcinoma with ingenol mebutate gel, $0.05 \%$. Clin Cosmet Investig Dermatol. 2016;9:205-209.

67. Ramsay JR, Suhrbier A, Aylward JH, et al. The sap from Euphorbia peplus is effective against human nonmelanoma skin cancers. Br J Dermatol. 2011;164(3):633-636.

68. Rowe DE, Carroll RJ, Day CL Jr. Long-term recurrence rates in previously untreated (primary) basal cell carcinoma: implications for patient follow-up. J Dermatol Surg Oncol. 1989;15(3):315328.

69. Cho M, Gordon L, Rembielak A, Woo TC. Utility of radiotherapy for treatment of basal cell carcinoma: a review. Br J Dermatol. 2014;171(5):968-973.

70. Lear W, Mittmann N, Barnes E, Breen D, Murray C. Cost comparisons of managing complex facial basal cell carcinoma: Canadian study. J Cutan Med Surg. 2008;12(2):82-87.

71. Von Hoff DD, LoRusso PM, Rudin CM, et al. Inhibition of the hedgehog pathway in advanced basal-cell carcinoma. N Engl J Med. 2009;361(12):1164-1172.

72. Jacobsen AA, Aldahan AS, Hughes OB, Shah VV, Strasswimmer J. Hedgehog pathway inhibitor therapy for locally advanced and metastatic basal cell carcinoma: a systematic review and pooled analysis of interventional studies. JAMA Dermatol. 2016;152(7):816-824.

73. Ally MS, Aasi S, Wysong A, et al. An investigator-initiated open-label clinical trial of vismodegib as a neoadjuvant to surgery for high-risk basal cell carcinoma. J Am Acad Dermatol. 2014;71(5):904-911.e901.

74. Pollom EL, Bui TT, Chang AL, Colevas AD, Hara WY. Concurrent vismodegib and radiotherapy for recurrent, advanced basal cell carcinoma. JAMA Dermatol. 2015;151(9):998-1001. 